\title{
Electricity Price Regulation and Electric Power Enterprises' Behaviors
}

\author{
Jinghong Zhou \\ School of Economics and Management, North China Electric Power University, Beijing 102206, China \\ E-mail: lnly1976@163.com
}

Yang $\mathrm{Hu}$

School of Economics and Management, Beihua University, Jilin 132013, China

\begin{abstract}
Because the electric power enterprises have natural monopoly characteristic, various states generally adopt the control to the electric power enterprise in order to limit their market influence. The electricity price control is one of electric power control ways. This paper briefly introduces the basic principle of the electricity price control, and the electric power enterprise behaviors has been made the long-term and the short-term analysis under the electricity price control, and the economic reason is analyzed that the electric power enterprises implement the power demand side management, and under the demand change the profit influence of the electric power enterprise is analyzed and the measure which possibly adopted by the electric power enterprise.
\end{abstract}

Keywords: Monopoly, Electricity price regulation, Power demand side management, Economic analysis

Electric power enterprise is one of the important base industries relating to national economy and social development, and it is also one of the pubic utilities relating to national interest and people's livelihood. Electric power is the necessary material base for the society and the economy, people's daily life, and various industries to survive. With the development of the marketization reform of the electric power, the marketization of the electric power will be enhanced gradually. But electric power enterprises' characteristic of natural monopoly is still hard to change, and various countries still generally control electric power enterprises. The electricity price regulation is one of main forms of the electric power control, to study electric power enterprises' behaviors under the electricity price regulation could make for the analysis of the influence of the electricity price policy on electric power enterprises, and the prediction of electric power enterprises' behaviors and their profits when the demands change, and help the supervision departments to predict the policy effect when they regulate the electricity price.

\section{Basic principles of the electricity price regulation}

At present, most electric power enterprises are in the sate of natural monopoly, so even if there is no regulation, electric power enterprises would make the decision to realize their own maximum profits in the monopoly market structure. According to the economics principle, the condition that enterprises realize the maximum profit is that the marginable revenue (MR) equals to the marginable cost (MC).

$$
M R=\frac{\Delta R}{\Delta Q}=\frac{\Delta(p \cdot Q)}{\Delta Q}=p+Q \frac{\Delta P}{\Delta Q}
$$

According to the definition of the price elasticity of demand $\left(E_{d}\right)$,

$$
\begin{aligned}
& E_{d}=\frac{p}{Q} \cdot \frac{\Delta Q}{\Delta P} \\
& \text { So, } M R=P+P\left(\frac{Q}{P} \cdot \frac{\Delta P}{\Delta Q}\right)=p+p \cdot\left(\frac{1}{E_{d}}\right) \\
& \text { When MR }=\text { MC, } P=\frac{M C}{1+\left(1 / E_{d}\right)}
\end{aligned}
$$

Because the electric price elasticity of demand generally is a small negative value, the electricity price made by the electric power enterprises according to the principle of maximum own profit (i.e. the formula (4)) would be far higher than the marginable cost. As seen in Figure 1, in the monopoly situation, $P_{m}$ is far higher than $P_{c}$, which means the electricity price is higher but the electric power supply is less in practice. 
In the complete competition market, the price of commodity equals the marginable revenue and the marginable cost of the commodity, i.e. $P=M R=M C$. According to the welfare economics principle, in the complete competition economy, the balance price of commodity could realize the Pareto optimality of production and exchange, so the market balance price in the complete competition economy is thought to be most effective. The commodity price made by the monopoly enterprise will usually exceed its marginable cost to get the monopoly profit, but the monopoly profit is generally thought to be unfair, and the monopoly will also induce that the resource allocation lacks in efficiency. The monopoly force is usually measured by the Lerner index $(L)$, i.e.

$$
L=\frac{P-M C}{p}=-\frac{1}{E_{d}}
$$

From the above formula, the Lerner index is the reciprocal of the electric price elasticity of demand. Because the electric power demand has large rigidity, and the electric price elasticity of demand is small, so the Lerner index of electric power enterprise is big, which means the monopoly force of electric power enterprise is large. Therefore, various governments in the world generally regulate electric power enterprises to promote electric power enterprise to be more economic and effective.

When the long-term average cost and the marginable cost of electric power are all in the descending stage, according to the pricing method of the maximum profit, electric power enterprises hope that the electricity price is $P_{m}$, but to enhance the efficiency, the regulation department hopes that the electricity price is the corresponding price of the crossing point between the marginable cost curve and the demand curve, i.e. $P_{c}$, that could eliminate the monopoly force and realize the Pareto optimality. However, if the electricity price is $P_{c}$, the electricity price level is lower than the average cost (AC), that means electric power enterprise is in loss from the economics meaning, and the electric power enterprise would exit from this industry, so the regulation electricity price generally should be the corresponding electricity price of the crossing point of the average cost curve and the demand curve, i.e. $P_{r}$, which could not only make electric power enterprise to get normal economic profit, but also properly limit the monopoly force and expand the electric power supply. In the practice, the computation of the average cost is easier than the computation of the marginable cost, so most regulation electricity prices are priced according to the average cost.

Though in the long term, the production of electric power enterprises is made at the crossing point of the average cost curve and the demand curve, but the short-term cost curve of electric power enterprises is completely different, because if the electric power enterprise wants to expand the electric power output in the short term, it must run the electricity generation equipment with higher cost, and the cost will be ascending accordingly. Therefore, the short-term cost curve is similar with the curve of other commodities. From the formula (1), in the condition of electricity price regulation, the marginable revenue of electric power enterprise equals the regulation electricity price, i.e. $M R=p_{r}$, and according to the condition of maximum profit, the decision-making point of electric power enterprise's output is the corresponding output of the regulation electricity price on the marginable cost curve (seen in Figure 2), and here, the profit of electric power enterprise is the area surrounding $\mathrm{A}, \mathrm{B}, \mathrm{E}_{0}$, and $\mathrm{P}_{\mathrm{r}}$.

\section{Analysis of the behaviors that the electric power enterprises implement the demand side management}

\subsection{Electric power demand side management}

Because the construction period to expand the production capacity of electric power is long, and the supply of electric power has the supply limit in the short term, and the demand of electric power has certain rigidity, and when the electric power department could not satisfy short-term electric power supply, it wants to start from the electric power demand side management to reduce the electric power demand and maintain the balance of supply and demand. According to the definition of the State Grid Corporation of China, the electric power demand side management means the power management activities to induce electric power customers to change the power use mode by adopting effective encouragement measure, enhance the power using efficiency of the terminal users, optimize the resource allocation, improve and protect the environment, and realize the electric power service with minimum cost.

Common commodity could bring efficiency for consumers, or provide production factor for producers, but the electricity power should be realized by the electricity using equipment to realize above two intentions, and the electricity demand side management should be mainly implemented by enhancing the electric power using efficiency and mode of the power using equipments to reduce the electric power demand, not rationing, resting sequentially, or changing shifts which could not consider users' bearing ability and economic benefit, and more by scientific management method and advanced technical measure, and without changing normal production 
order and living rhythm, users should be encouraged to actively change the consumption behaviors and power using mode, enhance the power using efficiency, and reduce the electric power demand.

\subsection{Economic analysis of the electric power demand side management behaviors}

From the analysis of electric power enterprises' short-term behaviors in the regulation of electricity price, in the short term, electric power enterprises' output is the corresponding electric power output of the regulation electricity price on the marginable cost curve. But the demand of electric power is the corresponding electric energy of the regulation electricity price on the demand curve. When the demand electric energy exceeds the optimal electric supply of electric power enterprises, they have to run the electricity generation equipment with higher cost to satisfy the supply of electric power, and electric power enterprises would deviate from the output decision of maximum profit. Here, electric power enterprises hope approaching the decision point of maximum profit by reducing the demand of electric power, and only if the cost increased by reducing the electric power demand is less than the profit increased by the decrease of the electric power demand, and here, electric power enterprises would adopt measures to cut the demand of electric power, i.e. implementing the electric power demand side management.

\section{Analysis of electric power enterprises' behaviors under changeable demands}

Because the electric power demand changes largely in short term, it is necessary to analyze electric power enterprises' behaviors in the short term when the demand is changeable. When the electric power enterprise's production cost and the regulation electricity price are fixed, the analysis result of the electric power enterprise's profit and measures when the electric power demand changes is seen in Figure 3.

When the electric power demand is less than the electric power enterprise's optimal decision output $q_{0}$ (at the point of $E_{3}$ in Figure 3), the electric power enterprise's profit is less than the profit with the optimal output, and here, electric power enterprises will promote the electric power consumption by various measures to realize the enterprise's maximum profit. Specially, if the electric power demand is less than the electric power quantity decided by the average cost and regulation electricity price (at the point of $E_{4}$ in Figure 3), the electric power enterprise's average cost will exceed the regulation electricity price, and the electric power enterprise will be in loss in economics meaning, and on the one hand, it will encourage the consumption of electric power by various measures, and on the other hand, it will reduce the supply scale of electric power.

When the electric power demand equals the optimal decision output of the electric power enterprise (at the point of $E_{0}$ in Figure 3), the profit level of the electric power enterprise will achieve maximum level, and the enterprise generally will not adopt any measure.

When the electric power demand exceeds the optimal decision output of the electric power enterprise (at the point of $E_{l}$ in Figure 3), the profit level of the electric power enterprise will be less than the profit level with the optimal output, and here, the electric power enterprise would reduce the electric power consumption by various measures, and when the charge of reducing the electric power consumption is less than the profit obtained by the electric power enterprise because of the decrease of the electric power demand, the electric power enterprise will actively implement the measure of the electric power demand side management to expand the profit level of the enterprise. In special, if the electric power demand exceeds the electric power quantity decided by the electric power enterprise's average cost and the regulation electricity price (at the point of $E_{2}$ in Figure 3), the enterprise's average cost will exceed the regulation electricity price, and the enterprise will be in loss in economics meaning, and on the one hand, the electric power enterprise would cut the electric power demand by various means and implement more powerful measure of electric power demand side management, and on the other hand, it will expand the supply scale of the electric power to reduce the enterprise's average production cost.

Because the change of the electric power demand is quick in short term, and it may even fluctuate at the optimal output in one day, therefore, in the short term, the electric power enterprise implements the measure of the electric power demand side management, and the main intention is to control the electric power demand near the optimal output to realize the enterprise's maximum profit. For the areas with large load fluctuation, the electric power enterprise will adopt the measure of transferring peak to fill valley first, which could not stabilize the electric power demand, but also enhance the load rate of the electric power grid, enhance the safety of the electric power system, and reduce the reserve investment of the electric power system.

\section{Actuality and problems about the electricity price regulation of China}

At present, the "unbundling generation and grid" has been realized in the electric power system reform of China, and the price competition has been implemented on the power generation side, and as the natural monopoly 
enterprise, the grid enterprises have been supervised by the government. China has paid more attention to the electricity price reform in the electric power system reform, and studied the reform of the feed-in tariff, the power transformation and distribution price, and the sales price. But the mode of the regulation of the electricity price has not been specially confirmed in Chinese laws, regulations, and reforms. For example, in the "Electricity Law of China" only regulated that "making price should reasonably compensate the cost, confirm the income, count the tax according to the law, insist the fair loading, and promote the electric power construction". In some documents, the electricity price should be divided into the feed-in tariff, the power transformation and distribution price, and the sales price, where, the generation electricity price and the sale price were formed in the market competition, and the transmission and distribution electricity price was regulated by the government, but what mode the government was referred to make the price is still not clear. The sales electricity price in China is divided into the regulation electricity price and the guidance electricity price. The former price is based on the catalog electric power price table issued by the National Development and Reform Committee every year, and the relative departments in various areas added various associate charges and make-ups into the regulation electricity price. And the guidance price includes the regulation electricity price, and when users' yearly power using quantity exceeds certain quantity, the price will add various associate charges and make-ups.

In the present situation of "unbundling generation and grid", most feed-in tariff still continue to use the past policy of "one price one factory", even "one price one machine", and the competition could not been effectively developed on the electricity generation side, so for those enterprises in the grid, the cost of purchasing the electric power is fixed basically, and their profits are mainly determined by the power sales quantity and the sales price, and in the situation of the regulation of sales electricity price, the only one way to increase the profit for grid enterprises is to expand the sales of the electric power. Though China regulated that the implementation body of the electric power demand side management is the State Grid Corporation of China, but in the practice, except when the electric power is deficient, various local grid enterprises would emphasize the electric power demand side management, in other periods, the implementation of the electric power demand side management is not active, and the main reason is that the implementation of the electric power demand side management would reduce the sales quantity of the grid enterprise, and further influence the profit level of the grid enterprise.

\section{Trends and policy suggestions of the electricity price reform of China}

With the development of the electric power system reform, the feed-in tariff competition mechanism on the electricity generation side will be implemented gradually, which could promote the effective competition on the power generation side. In this mechanism, in the load peak term, the grid enterprises must purchase the electric power with higher cost, and the price will certainly be higher than the electricity purchasing price in the load valley term, and by this competition form, the power generation side would transfer the electric power commodity to the grid enterprise by the price with the market efficiency, and the grid enterprises' various economics characteristics are consistent with the former analysis, and the cost curve is basically consistent with the former analysis result. According to the former analysis, by analyzing the grid enterprise' profit change under different regulation prices, the proper regulation electricity price policy could be made to effectively encourage the grid enterprises to implement the measure of the electric power demand side management.

According to relative documents of the electric power system reform, the sales price is finally determined by the market competition, but because of the natural monopoly characteristic of the grid enterprises, even in the developed countries with healthy market mechanism, this situation has not be formed completely, so it is more difficult and long process in China, and in the present state or the forecasted future, the regulation is the main mode, but the regulation may not include the single electricity price, but include the loose regulation in certain range, for example, the electricity price is allowed to fluctuate in certain range, and the government will implement the timing price, peak and valley price, and the response price. No matter what the form of regulation electricity mode changes, the electric power enterprise' marginable income always equals the regulation electricity price, and only with the definite regulation price curve, the former analysis is still effective, i.e. the electric power enterprise's optimal output decision point is still the crossing point of the marginable cost curve and the regulation electricity price curve.

The electric power department is the main energy consumption department, and above $70 \%$ of electric power generation comes from petrifaction energy, and the effective using and saving of the electricity generation will be important to accomplish the targets for saving energy and reducing emissions for China. Aiming at how to reasonably make the sales electricity price regulation policy and encourage electricity generation departments and electric power users to actively adopt the power saving measures, following suggestions are proposed.

(1) Perfecting the feed-in tariff competition mechanism on the electricity generation side 
The feed-in tariff competition mechanism is the basic form to realize the effective competition on the electricity generation side, which could not promote the competition on the electricity generation side and strengthen the management efficiency of the electricity generation side, but also make the grid enterprises to more emphasize the influence of the electricity purchasing cost on the profit and change the grid enterprises' motivation of blindly expanding the sales of power to realize the maximum profit, so the government could use the electricity sales price to promote the grid enterprise to implement the measure of the electric power demand side management.

(2) Establishing the efficiency management mechanism giving priority to the grid enterprise

At present, though China regulated that the implementation object of the electric power demand side management is the grid enterprises, but the corresponding encouragement policies have not been issued. Because one of the targets to implement the electric power demand-side management is to reduce users' power using level, that will certain reduce the grid enterprises' income. To solve this problem, the foreign power enterprises' method of departing the income from the sales quantity of power could be referred, and the regulation electricity price could be used to confirm the electric power enterprises' income level, and the electric power enterprises' energy-saving investment would be the investment which could obtain the income, so the grid enterprises would have the enthusiasm to implement the electric power demand side management.

(3) Establishing the response mechanism of the electric power demand side

Based on the electricity price, the electric power demand side response mechanism could influence the time and level of the electric power demand, fully utilize the function of the electricity price to adjust the demand, induce users to use the power reasonably, so the random electric power load change will be the change which could be managed, and the random power generation using renewable resources could be utilized to the largest extent.

(4) Quickening the construction of the smart grid

On the electricity sales side, the intelligent grid could provide material bases for electric power enterprises and users to communicate, and provide the material guarantee to implement the timing electricity price more effectively.

\section{References}

Cao, Shiguang \& Zhang, Dongxiao. (2001). The Analysis of Economic Activities Should Be Strengthened. China Power Enterprise Management, No.4.

Huang, Zhanwei \& Xin, Yaqin. (1996). Analysis of Electric Power Enterprises' Economic Activity. Qinghai Electric Power, No.3.

J. N. Sheen. (2005). Economics Profitability Analysis of Demand Side Management. Energy Conversion and Management, No.46. P.2919-2935.

Robert, S. Pindyck \& Daniel, L. Rubinfeld. (2000). Micro Economics (4'th Edition). Beijing: China Renmin University Press.

Yang, Suping, Zhao, Yongliang \& Fu, Shujie. (2006). Economic Activity Analysis and Comprehensive Plan Management for Power Enterprise under Power Market Environment. Electric Power Technologic Economics, No.18(5). 


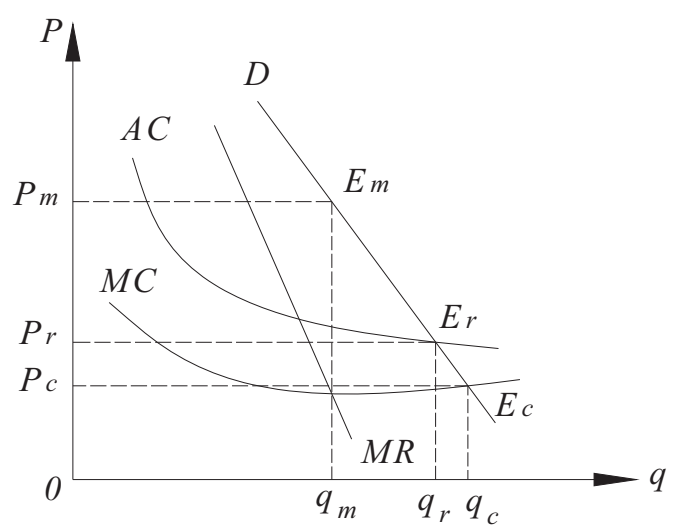

Figure 1. Electricity Price Regulation of Electric Power Enterprises

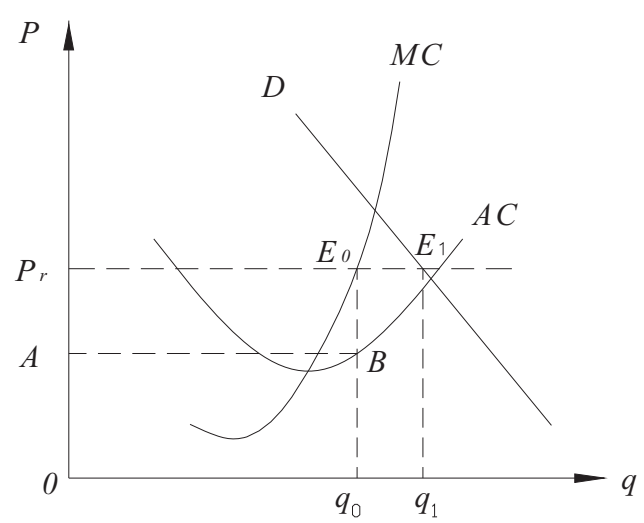

Figure 2. Electric Power Enterprises' Short-term Output Decisions under Electricity Price Regulation

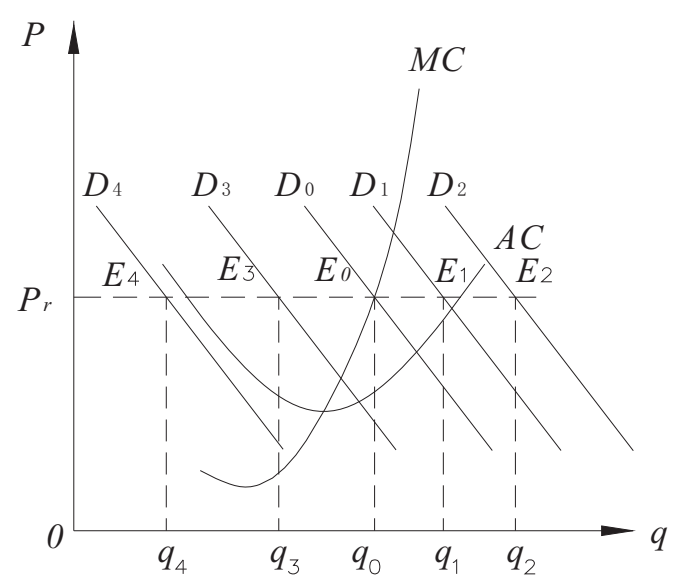

Figure 3. Analysis of Electric Power Enterprises' Behaviors under Changeable Demands 